\title{
Development
}

\section{Atypical Cadherin FAT3 Is a Novel Mediator for Morphological Changes of Microglia}

\author{
Tomomi Okajima, ${ }^{2}$ Yichen Gu, ${ }^{2}$ Rin-ichiro Teruya, ${ }^{3}$ Sarasa Yano, ${ }^{2}$ Takumi Taketomi, ${ }^{3}$ Ban Sato, ${ }^{1}$ \\ Tomoki Chiba, ${ }^{1,4}$ and Fuminori Tsuruta ${ }^{1,4,5}$
}

\section{https://doi.org/10.1523/ENEURO.0056-20.2020}

${ }^{1}$ Faculty of Life and Environmental Sciences, University of Tsukuba, Tsukuba, Ibaraki 305-8577, Japan, ${ }^{2}$ Graduate School of Life and Environmental Sciences, University of Tsukuba, Tsukuba, Ibaraki 305-8577, Japan, ${ }^{3}$ College of Biological Sciences, School of Life and Environmental Sciences, University of Tsukuba, Tsukuba, Ibaraki 305-8577, Japan, ${ }^{4}$ Ph.D. Program in Human Biology, School of Integrative and Global Majors, University of Tsukuba, Tsukuba, Ibaraki 305-8577, Japan, and ${ }^{5}$ Master's and Doctoral Program in Neuroscience, Graduate School of Comprehensive Human Sciences, University of Tsukuba, Tsukuba, Ibaraki 305-8577, Japan

\begin{abstract}
Microglia are resident macrophages that are critical for brain development and homeostasis. Microglial morphology is dynamically changed during postnatal stages, leading to regulating synaptogenesis and synapse pruning. Moreover, it has been well known that the shape of microglia is also altered in response to the detritus of the apoptotic cells and pathogens such as bacteria and viruses. Although the morphologic changes are crucial for acquiring microglial functions, the exact mechanism which controls their morphology is not fully understood. Here, we report that the FAT atypical cadherin family protein, FAT3, regulates the morphology of microglial cell line, BV2. We found that the shape of BV2 becomes elongated in a high-nutrient medium. Using microarray analysis, we identified that FAT3 expression is induced by culturing with a high-nutrient medium. In addition, we found that purinergic analog, hypoxanthine, promotes FAT3 expression in BV2 and mouse primary microglia. FAT3 expression induced by hypoxanthine extends the time of sustaining the elongated forms in BV2. These data suggest that the hypoxanthine-FAT3 axis is a novel pathway associated with microglial morphology. Our data provide a possibility that FAT3 may control microglial transitions involved in their morphologic changes during the postnatal stages in vivo.
\end{abstract}

Key words: FAT3; HPRT1; hypoxanthine; Lesch-Nyhan syndrome; microglia; morphogenesis

\section{Significance Statement}

Microglia play an important role in regulating neural circuit formation and brain homeostasis. Microglial morphology is greatly changed from reactive form to surveillant form after birth. Intriguingly, these morphologic changes are tightly associated with regulating higher brain functions. However, the mechanisms of morphologic changes have not been elucidated. Here, we report that atypical cadherin family protein, FAT3, is a novel regulator for microglial morphology. We found that FAT3 expression is induced by purinergic derivative, hypoxanthine, and is necessary for sustaining microglial morphology after changing to elongated shapes in vitro. Because both purinergic metabolism and FAT3 pathway have been implicated in neurodevelopmental disorders, our findings may shed light on the novel approach for treating these disorders associated with a microglial abnormality.

Received February 16, 2020; accepted August 20, 2020; First published August 31, 2020.

The authors declare no competing financial interests.
Author contributions: T.O. and F.T. designed research; T.O. and Y.G. performed research; T.O., R.-i.T., S.Y., T.T., B.S., T.C., and F.T. analyzed data; T.O. and F.T. wrote the paper. 


\section{Introduction}

Microglia play important roles in regulating not only the immune system but also neural circuit construction in the CNSs (Kettenmann et al., 2011). Previous study has reported that microglia exhibit the amoeboid shape during prenatal period and gradually transform into ramified shape around postnatal day (P)14. Usually, amoeboid microglia are thought to be reactive forms, which possess a high ability for engulfment. Because neuronal cell deaths frequently occur during the developmental stages, reactive microglia eliminate the apoptotic or vulnerable neurons to regulate the number of neurons and brain environments (Marín-Teva et al., 2004; Cunningham et al., 2013). On the other hand, microglia have been known to be involved in neural circuit formation through regulating neuronal survival, apoptosis, synaptogenesis, and synapse pruning (Marín-Teva et al., 2004; Sierra et al., 2010; Paolicelli et al., 2011; Cunningham et al., 2013; Ueno et al., 2013; Miyamoto et al., 2016). In particular, the control of synaptic connectivity is a key process that underlies the higher brain functions. Previous studies have shown that the number of synapses is dramatically increased during brain development, followed by reducing them by microglia (Huttenlocher and Dabholkar, 1997; Paolicelli et al., 2011; Schafer et al., 2012). In the case of normal development in mice, the synaptic pruning occurs approximately from P20 to P30. At this time, microglial morphology exhibits the ramified shape, which is a surveillance mode. Ramified microglia constantly elongates and retracts their processes to monitor the neural circuit even in the resting state (Nimmerjahn et al., 2005; Haynes et al., 2006). Finally, microglia contribute to the proper neural circuit formation by removing unnecessary synapses (Paolicelli et al., 2011; Schafer et al., 2012). It is thought that these morphologic alterations in microglia are tightly regulated not only by genetic programs but also by various factors, such as metabolites and exogenous factors, followed by constructing precise neural circuit and maintaining normal brain functions. Although the morphologic changes of microglia are implicated in their activity, the cues that modulate microglial morphology, particularly the intrinsic substances, have not been fully explicated.

The cadherin family proteins play an important role in brain development, such as synapse connectivity and neural circuit formation (Takeichi, 2007). In addition, mutations in cadherin family genes cause psychiatric and

This work was supported by Grant-in-Aid from the Ministry of Education, Science, Sports and Culture of Japan JSPS KAKENHI (24111504, 16KK0158); the Astellas Foundation for Research on Metabolic Disorders (F.T.); and by the JSPS Research Fellowship for Young Scientists (18J20536) (T.O.).

Acknowledgements: We thank the lab members for helpful discussions and technical supports and Jiwoo Kim for critical reading of this manuscript.

Correspondence should be addressed to Fuminori Tsuruta at tsuruta. fuminori.fn@u.tsukuba.ac.jp.

https://doi.org/10.1523/ENEURO.0056-20.2020

Copyright (C) 2020 Okajima et al.

This is an open-access article distributed under the terms of the Creative Commons Attribution 4.0 International license, which permits unrestricted use, distribution and reproduction in any medium provided that the original work is properly attributed. developmental disorders, including schizophrenia and autism spectrum disorder (ASD) (Redies et al., 2012). Thus, cadherin proteins in the brain are crucial for acquiring proper brain functions. So far, several groups have reported that atypical cadherins are expressed in the CNS and tightly regulate brain development. FAT3, which is one of the four FAT-related genes (Fat1-Fat4), is known to be abundantly expressed in the mammalian brain (Nagae et al., 2007; Zhang et al., 2014). Fat3 gene encodes the transmembrane protein that possesses large extracellular domains and is an ortholog of the Drosophila fat-like gene. In Drosophila, Fat-like induces aberrant actin filament orientation in the ovary (Viktorinová et al., 2009). In the CNS, FAT3 is mostly expressed in neurons (Zhang et al., 2014, 2016) and regulates neuronal morphology in the retina (Deans et al., 2011; Krol et al., 2016). On the other hand, the functions of FAT3 in microglia have not been elucidated although FAT3 is expressed in microglia during the postnatal stage (Bennett et al., 2016).

Recent studies have reported that purinergic signaling plays an important role in regulating aspects of microglia under brain development (Fields and Burnstock, 2006). Purine derivatives, including ATP and ADP, are released from cells to the extracellular region and activate microglia via purinergic receptors, and thus it is crucial for various physiological processes in the CNS. Hypoxanthine, one of the purine derivatives, is implicated in brain development under the postnatal stage. For instance, newborns of mammals are exposed to hypoxic conditions at the time of birth, and hypoxanthine may become a marker of hypoxia. Indeed, abnormal hypoxic conditions trigger aberrant brain development (Saugstad, 1988). Moreover, it is known that perturbed hypoxanthine concentration is tightly associated with ASD (Gevi et al., 2016). Thus, precise regulation of purine derivatives, such as hypoxanthine, is essential for the normal brain development.

In this study, we found that the expression of atypical cadherin, FAT3, alters the morphology of microglia BV2 cells. Moreover, hypoxanthine induces FAT3 expression associated with their morphology. Our data provide the first evidence that links nucleic acid metabolism in microglia to their morphologic regulation.

\section{Materials and Methods}

\section{Cell culture and stimulation}

BV2 cells were cultured in either DMEM (high glucose; Wako) or DMEM/nutrient mixture F-12 (DMEM/F12; Thermo Fisher Scientific) containing $10 \%$ fetal bovine serum (FBS), 100 units penicillin and $100 \mathrm{mg}$ streptomycin (P/S; Thermo Fisher Scientific). For screening, BV2 cells were cultured in DMEM with $10 \%$ FBS and P/S in the presence or absence of $150 \mu \mathrm{M} \mathrm{L-alanine} \mathrm{(Wako),} 50 \mu \mathrm{M}$ L-glutamic acid (Wako), $50 \mu \mathrm{M}$ L-aspartic acid (Wako), 50 $\mu \mathrm{M}$ L-asparagine (Wako), $150 \mu \mathrm{M}$ L-proline (Wako), 0.0052 $\mathrm{pM} \mathrm{CuSO}_{4}$ (Wako), $1.5 \mathrm{pM} \mathrm{FeSO}_{4}$ (Wako), $1.5 \mathrm{pM} \mathrm{ZnSO} 4$ (Wako), $150 \mathrm{nM}$ linoleic acid (Wako), $500 \mathrm{nM}$ lipoic acid (Sigma), $15 \mathrm{nM}$ biotin (Sigma), $500 \mathrm{nM}$ vitamin B12 (Wako), and $15 \mu \mathrm{M}$ hypoxanthine (Sigma). Pyridoxalphosphate-6azophenyl-2',4'-disulfonic acid tetrasodium salt (PPADS) was 
purchased from Alexis Corporation. Dipyridamole (DY) and allopurinol (ALP) were purchased from Tokyo Chemical Industry. Hoechst 33342 was purchased from Thermo Fisher Scientific. DAPI was purchased from Dojindo. FAT3 siRNAs (NM_001080814, siRNA ID; SASI_ Mm02_00293873) and MISSION siRNA universal negative control (SIC001) were purchased from Sigma; $50 \mathrm{nM}$ FAT3 siRNAs were transfected using Lipofectamine RNAi Max Reagent (Thermo Fisher Scientific) according to the manufacturer's instructions.

\section{Plasmid construction and antibody}

A cDNA fragment encoding a $C$ terminus (CT) of human-FAT3 containing 276 residues (4313-4589 amino acid) was amplified from FAT3 cDNA (product ID: ORK04991; Kazusa) and subcloned into the BamHI site of pET28(a) and the Bglll site of pCS4-HA. The primers used were as follows:

FAT3_HA forward, 5'-AAGGATCCGCCACCCGCAAGA AGGTCTTCCGC-3';

FAT3_HA reverse, 5' -CCGGATCCCTACACTTGAGTCT GATGCTGAGTCTCCAC-3';

FAT3_recombinant forward, 5'-AAGGATCCGCCAC CCGCAAGAAGGTCTTCAGAAAG-3';

FAT3_recombinant reverse, 5'-AAGGATCCCTACACC TGGGTCTGCTGCTGTG-3'.

The His-tagged recombinant protein was produced in Escherichia coli BL21. The His-tagged FAT3 recombinant protein was purified using a Ni-Sepharose 6 Fast Flow (GE Healthcare), emulsified with Freund's complete and incomplete adjuvant (Difco Laboratories), and was injected intradermally into female New Zealand white rabbits (Kitayama Labes). The FAT3 antibodies were purified by fractionation with ammonium sulfate $(0-40 \%$ saturation), followed by immunoaffinity chromatography on a CNBr-activated Sepharose 4B (GE Healthcare) column that had been conjugated with GST-fused FAT3 CT protein carrying the $\mathrm{C}$-terminal 276 -residues sequence. FAT3 C-terminal antibody was concentrated $5 \times$ with a Vivaspin100K (GE Healthcare). For immunoblot analyses, anti-HA (3F10, Roche) and anti-tubulin (DM1A, Sigma) antibodies were used as a primary antibody.

\section{RT-qPCR}

BV-2 cells $\left(1.5 \times 10^{5}\right.$ cells $/ 60-\mathrm{mm}$ dish) were cultured for $24 \mathrm{~h}$ at $37^{\circ} \mathrm{C}$ with $5 \% \mathrm{CO}_{2}$ and treated with various stimulations for $24 \mathrm{~h}$. Total RNAs from cells were isolated by ISOGEN II (NIPPON GENE) according to the manufacturer's instructions. The cDNAs were synthesized by reverse transcriptase, 100 units ReverTra Ace (TOYOBO) together with $25 \mathrm{pmol}$ Random Primer (nonamer; TOYOBO), $20 \mathrm{nmol}$ dNTPs and $1.0 \mu \mathrm{g}$ total RNAs. The qPCR was performed in triplicate in 96-well plate (Thermo Fisher Scientific) using THUNDERBIRD SYBR qPCR Mix (TOYOBO) in Thermal Cycler Dice Real Time System TP800 (TAKARA) or Applied Biosystems 7900HT Fast Real Time PCR System (Applied Biosystems). The relative quantity of the target expression was calculated by $2^{-\Delta \Delta \mathrm{Ct}}$ methods using Thermal Cycler Dice Real Time System Software
(TAKARA) or SDS Software 2.4.2 (Applied Biosystems) with the following calculation. The relative quantity $=2^{-\Delta \Delta \mathrm{Ct}}$, $\Delta \Delta \mathrm{Ct}=\left(\mathrm{Ct}^{\text {target }}-\mathrm{Ct}^{5 \mathrm{~S}}\right)$ sample $-\left(\mathrm{Ct}^{\text {target }}-\mathrm{Ct}^{5 \mathrm{~S}}\right)_{\text {reference; }} \mathrm{Ct}$, threshold cycle.

The primers used were as follows:

FAT3 forward, 5'-TATAGGAACGTGCGCTGCACCTGT AATG-3';

FAT3 reverse, 5'-TCATAGCCCACACATTGCATGTCCT CTG-3';

5S rRNA forward, 5'-CGGCCATACCACCCTGAAC-3'; $5 S$ rRNA reverse, 5'-GCGGTCTCCCATCCAAGTAC-3';

\section{Morphologic assay}

BV2 cells were plated at the density of $5.0 \times 10^{4}$ cells $/ 35$ $\mathrm{mm}$ dish under DMEM/F12 and incubated for $24 \mathrm{~h}$ at $37^{\circ} \mathrm{C}$ with $5 \% \mathrm{CO}_{2}$. The DMEM/F12 media were replaced with either DMEM or DMEM/F12 in the presence or absence of each stimulation, and cells were incubated for $24 \mathrm{~h}$. The images were collected using BIOREVO BZ-9000 (Keyence) equipped with $20 \times \mathrm{S}$. Plan Fluor $0.45 \mathrm{NA}$ objective lenses (Nikon) controlled by BZ-Il software (Keyence). Cell shapes were quantified by FIJI ImageJ software and calculated Feret diameters as a parameter of morphology (https:// imagej.nih.gov/ij/docs/menus/analyze.html). To analyze the morphology, we took the 5-10 images $\left(2.0 \times 10^{5} \mu \mathrm{m}^{2} /\right.$ field $)$. The elongated cells were defined by a Feret diameter score higher than or equal to 2 . The number of samples in each experiment is given in Table 1.

\section{Immunoblot analysis}

HEK293T cells were plated at $5.0 \times 10^{5}$ cells on six-well plate and incubated at $37^{\circ} \mathrm{C}$ with $5 \% \mathrm{CO}_{2}$ for $1 \mathrm{~d}$. Cells were transfected using $1.0 \mu \mathrm{g} / \mu \mathrm{l}$ polyethyleneimine MAX (Polyscience) and collected with lysis buffer [20 mM Tris$\mathrm{HCl}$ (pH 8.0), $150 \mathrm{mM} \mathrm{NaCl}, 1 \mathrm{mM}$ EDTA, 0.5\% NP-40, and $1 \mathrm{mM}$ DTT]. Cell lysates were centrifuged at $14,000 \mathrm{rpm}$ for $5 \mathrm{~min}$. The supernatant was run on SDSPAGE for protein separation, followed by electrophoretic transfer to a polyvinylidene difluoride membrane (Pall). After $1 \mathrm{~h}$ blocking by $5 \%$ skim milk at room temperature, membranes were incubated with primary antibodies overnight at $4^{\circ} \mathrm{C}$. The proteins on membrane were then detected with HRP-conjugated secondary antibodies and chemiluminescence reagents [ECL Prime Western Blotting Detection Reagents (GE Healthcare) or ChemiLumi One Super (Nacarai tesque)].

\section{Immunocytochemistry}

BV2 cells were plated at $5.0 \times 10^{4}$ cells and incubated on $15 \mathrm{~mm}$ coverslips in 12 -well plates at $37^{\circ} \mathrm{C}$ with $5 \%$ $\mathrm{CO}_{2}$ in each condition. The cells were fixed with $4 \%$ paraformaldehyde (Merck KGaA) in PBS for 10 min at room temperature. The coverslips were washed in PBS and blocked with $5 \%$ bovine serum albumin (BSA; Wako) in PBS with $0.4 \%$ Triton X-100 (MP Biomedicals), then incubated with the FAT3 antibody $(1: 250)$ for overnight at $4^{\circ} \mathrm{C}$. After a PBS wash, samples were incubated with the secondary antibody; Alexa Fluor 488 anti-rabbit IgG (1:500; Thermo Fisher Scientific) for $30 \mathrm{~min}$ at room temperature 
Table 1: The number of cells counted for the morphology assay

\begin{tabular}{|c|c|c|c|c|c|c|c|c|c|c|c|}
\hline \multicolumn{12}{|l|}{ Figure $1 B$} \\
\hline Field number & 1 & 2 & 3 & 4 & 5 & & & & & & \\
\hline DMEM/F12 & 78 & 98 & 121 & 102 & 84 & (cells) & & & & & \\
\hline Field number & 1 & 2 & 3 & 4 & 5 & 6 & 7 & 8 & 9 & 10 & \\
\hline DMEM + siControl & 65 & 67 & 59 & 69 & 83 & 32 & 35 & 50 & 47 & 47 & \\
\hline DMEM/F12+siControl & 71 & 53 & 73 & 60 & 73 & 96 & 66 & 65 & 92 & 72 & \\
\hline Field number & 1 & 2 & 3 & 4 & 5 & & & & & & \\
\hline DMEM & 109 & 109 & 81 & 134 & 99 & & & & & & \\
\hline DMEM/F12 & 155 & 136 & 127 & 131 & 129 & & & & & & \\
\hline $\mathrm{DMEM}+\mathrm{HYP}$ & 91 & 131 & 75 & 68 & 78 & (cells) & & & & & \\
\hline \multicolumn{12}{|l|}{ Figure $3 C$} \\
\hline Field number & 1 & 2 & 3 & 4 & 5 & & & & & & \\
\hline \multicolumn{12}{|l|}{ Figure $3 \mathrm{H}$} \\
\hline Field number & 1 & 2 & 3 & 4 & 5 & & & & & & \\
\hline DMEM & 79 & 92 & 110 & 117 & 108 & & & & & & \\
\hline DMEM+DY & 105 & 157 & 146 & 173 & 103 & (cells) & & & & & \\
\hline \multicolumn{12}{|l|}{ Figure $3 K$} \\
\hline Field number & 1 & 2 & 3 & 4 & 5 & & & & & & \\
\hline DMEM & 120 & 79 & 111 & 94 & 120 & & & & & & \\
\hline DMEM + ALP & 138 & 168 & 115 & 104 & 104 & (cells) & & & & & \\
\hline \multicolumn{12}{|l|}{ Figure $4 F$} \\
\hline Field number & 1 & 2 & 3 & 4 & 5 & & & & & & \\
\hline DMEM (conditioned) & 72 & 64 & 57 & 103 & 52 & & & & & & \\
\hline DMEM/F12 (conditioned) & 43 & 39 & 123 & 87 & 63 & & & & & & \\
\hline DMEM+HYP (conditioned) & 61 & 72 & 91 & 77 & 89 & & & & & & \\
\hline
\end{tabular}

in blocking solution. Cells were imaged with a confocal laser scanning fluorescence microscopy (LSM700; Carl Zeiss) and BIOREVO BZ-9000 (Keyence).

\section{Microarray analysis}

BV2 cells were plated at $3.0 \times 10^{5}$ cells on a $60 \mathrm{~mm}$ dish in the DMEM/F12, and culture media were exchanged with either DMEM or DMEM/F12 on the next day. After $1 \mathrm{~d}$ of incubation, total RNAs were extracted using ISOGEN II (NIPPON GENE) according to the manufacturer's instructions. The single-stranded cDNAs were generated from total RNA (100 ng) using Ambion WT Expression kit (Ambion Inc), sequentially fragmented and covalently linked to biotin using GeneChip WT Terminal Labeling and Hybridization kit (Affymetrix) according to the manufacturer's instructions. These samples were incubated at $45^{\circ}$ $\mathrm{C}$ at $60 \mathrm{rpm}$ for $17 \mathrm{~h}$ to hybridize on Affymetrix GeneChip Mouse Gene 1.0 ST arrays. After hybridization, each probe array was washed and stained with Affymetrix GeneChip Fluidics Station 450, and scanned by Affymetrix GeneChip Scanner 3000. Data were analyzed with Affymetrix Expression Console software and Affymetrix Transcriptome Analysis Console. The GEO accession numbers for the array dataset are GSM4306479 and GSM4306480.

\section{Measurement of intracellular hypoxanthine concentration}

BV2 cells were incubated at $1.0 \times 10^{6}$ cells on a $100-$ $\mathrm{mm}$ dish in the DMEM together with $15 \mu \mathrm{M}$ hypoxanthine for $12 \mathrm{~h}$, sequentially treated with $10 \mu \mathrm{M}$ DY or $10 \mu \mathrm{M}$ ALP for $3 \mathrm{~h}$. BV2 cells were incubated with ice-cold xanthine assay buffer (BioVison) for $10 \mathrm{~min}$ on ice and subjected to measurement of intracellular hypoxanthine concentration according to the manufacturer's instructions of the xanthine/hypoxanthine colorimetric/fluorometric assay kit (BioVision).

\section{Live cell imaging analysis}

BV2 cells were plated at $1.0 \times 10^{5}$ cells in a $35 \mathrm{~mm}$ dish and incubated for $24 \mathrm{~h}$. Cells were replaced with DMEM containing $1.0 \mathrm{ng} / \mu \mathrm{l}$ LPS in the presence or absence of 15 $\mu \mathrm{M}$ hypoxanthine and were then subjected to the imaging analysis. Live cell imaging was conducted on BIOREVO BZ-9000 (Keyence) equipped with $20 \times$ S. Plan Fluor 0.45 NA objective lenses (Nikon) controlled by BZ-II 
software (Keyence). BV2 cells were imaged at one frame per $15 \mathrm{~min}$ for $12 \mathrm{~h}$. The images were analyzed using FIJI ImageJ software. Briefly, the Feret diameter in each cell was quantified using the function of Set Measurements in Fiji ImageJ. The elongated cells were defined by a Feret diameter score $\geq 3$.

\section{Primary culture microglia}

All animal experiments were conducted according to the guidelines for animal care and use. The monoclonal CD11b antibody is generated using the M1/70 hybridoma cell line (M1/70.15.11.5.2-f, Developmental Studies Hybridoma Bank, The University of lowa) grown in Hybridoma-SFM (Thermo Fisher Scientific). The medium containing the CD11b antibody was collected by centrifugation when cells were grown until confluent. One day before dissection of the mouse, the sterile 100-mm Petri dishes were coated by $6 \mathrm{mg} / \mathrm{ml}$ goat-anti-mouse IgG secondary antibody (Jackson ImmunoResearch) in a solution of $50 \mathrm{mM}$ Tris- $\mathrm{HCl}(\mathrm{pH} 9.5)$ for $1 \mathrm{~h}$ at $37^{\circ} \mathrm{C}$, followed by washing with PBS three times. The CD11b antibodies were added to the coated dishes and incubated overnight. ICR pups (P1-P3; SLC) were rapidly dissected to take out the brains. These brains were placed into ice-cold PBS and chopped with a scalpel blade and surgical scissors. The chopped brains were suspended in $5 \mathrm{ml}$ of ice-cold PBS containing 40 units DNasel (Wako) and were transferred to a Dounce homogenizer equipped with a loose pestle (DWK Life Sciences $\mathrm{GmbH}$ ). They were homogenized 10 times and were then centrifuged at $500 \times$ $g$ for $15 \mathrm{~min}$ at $4^{\circ} \mathrm{C}$. After discarding the supernatant, cell pellets were resuspended in $5 \mathrm{ml}$ of PBS containing $2 \mathrm{mg} / \mathrm{ml}$ peptone from milk solids (Sigma), and passed through a 70$\mu \mathrm{m}$ cell strainer (BD Biosciences). To conduct a positive selection, the cells were incubated on immunopanning dishes coated with the CD11b antibodies for 20 min at room temperature. Unattached cells and debris were removed by washing using PBS without $\mathrm{Ca}^{2+}$ and $\mathrm{Mg}^{2+} 10$ times. The attached cells on the immunopanning dishes were treated with $0.25 \%$ trypsin $/ 1 \mathrm{mM}$ EDTA for $1 \mathrm{~min}$ at $37^{\circ} \mathrm{C}$. After incubation, the trypsin was quenched by $4 \mathrm{ml}$ of DMEM with $10 \%$ FBS. The cells were centrifuged at $500 \times g$ for $15 \mathrm{~min}$ at $4{ }^{\circ} \mathrm{C}$ and resuspended with $1 \mathrm{ml}$ of DMEM with $10 \%$ FBS. For immunocytochemistry, the coverslips were coated with Bovine Collagen Coating Solution (CELL Applications) for $15 \mathrm{~min}$ at $37^{\circ} \mathrm{C}$. After aspirating the collagen spots, the suspended cells were immediately plated at $3.5 \times 10^{3}$ cells/ spot and incubated for $10 \mathrm{~min}$ at $37^{\circ} \mathrm{C}$. The attached cells were incubated under $500 \mu$ of either DMEM, DMEM/F12, or DMEM with $15 \mu \mathrm{M}$ hypoxanthine for $24 \mathrm{~h}$ at $37^{\circ} \mathrm{C}$ with $5 \% \mathrm{CO}_{2}$. For RNA isolation, the 24-well plate was coated with Bovine Collagen Coating Solution for $1 \mathrm{~h}$ at $37^{\circ} \mathrm{C}$. The cells were plated at $3 \times 10^{4}$ cells and incubated in either $500 \mu \mathrm{l}$ of DMEM, DMEM/F12, or DMEM treated with $15 \mu \mathrm{M}$ hypoxanthine for $24 \mathrm{~h}$ at $37^{\circ} \mathrm{C}$ with $5 \% \mathrm{CO}_{2}$.

\section{Statistical analysis}

All experiments were performed in at least two independent experiments. All statistical data were analyzed by using GraphPad Prism (GraphPad Software) compared by Student's $t$ test and one-way ANOVA. The statistical analyses of qRT-PCR are shown in Table 2.

\section{Results}

\section{FAT3 regulates BV2 morphology}

To understand the mechanisms of how microglial morphology is controlled, we cultured microglial cell line BV2 with either a standard medium, DMEM, or a high-nutrient medium, DMEM/F12. When BV2 were cultured in DMEM, most cells exhibited round shapes. On the other hand, when cells were cultured in DMEM/F12, the number of elongated cells was increased (Fig. $1 A-C$ ), indicating that microglial morphology is influenced by the surrounding culture condition.

Next, to investigate the specific genes regulating BV2 morphology under DMEM/F12 conditions, we conducted a microarray analysis. The global gene expression patterns were different for each condition. Some genes were significantly upregulated under DMEM/F12 (Fig. 1D; Extended Data Table 1-1). Although we found several interesting targets at least in this screening, one of the most interesting candidates is Fat3 gene. Because FAT3 has been reported to regulate neuronal morphology in retinal amacrine cells (Deans et al., 2011; Krol et al., 2016), we presumed that FAT3 also controls the microglial morphology. To confirm this idea, we surveyed the expression level of FAT3 in microglia using the Brain RNA-seq database (http://www.brainrnaseq.org/). Interestingly, FAT3 expression is augmented in correlation with the timing of microglial transition around P14 (Fig. 1E), suggesting that FAT3 is a potential candidate, which controls microglial morphogenesis. Then, we confirmed whether FAT3 expression in BV2 cells is affected by culture condition. FAT3 expression was upregulated when BV2 cells were cultured in DMEM/F12 (Fig. 1F). Particularly, it seems likely that DMEM/F12 facilitates FAT3 clustering in a distal process and a leading edge of lamellipodia. Also, FAT3 showed polarized localization in the cell body (Fig. 1G,H), demonstrating that DMEM/F12 regulates FAT3 expression locally. We next investigated whether FAT3 is necessary for regulating their morphology. To do this, we first checked the efficiency of FAT3 siRNA. Treatment with siRNA significantly reduced DMEM/F12-induced expression levels of mRNA and changed immunostaining patterns in BV2 cells (Fig. $1 /, J$ ). Using this siRNA, we examined the necessity of FAT3 for regulating BV2 morphology. We found that FAT3 siRNA significantly suppressed the morphologic changes even in DMEM/F12 culture conditions (Fig. $1 K-M$ ), suggesting that FAT3 regulates BV2 morphology depending on the culture condition.

\section{Hypoxanthine promotes FAT3 expression in microglia}

We next investigated which factors in DMEM/F12 are implicated in FAT3 expression in BV2 cells. To examine this, we divided the specific components of DMEM/F12, which are not included in DMEM, into three groups (i.e., non-essential amino acids, metallic ions, the others; Fig. $2 A$ ), treated BV2 with them, and quantified the amount of 
Table 2: Statistical analysis for the qPCR experiments

\begin{tabular}{|c|c|c|c|c|c|c|c|}
\hline \multicolumn{8}{|l|}{ BV-2 qPCR (Fig. 1F) } \\
\hline Unpaired $t$ test & $\begin{array}{l}\text { Mean } \\
\text { difference }\end{array}$ & $95.00 \% \mathrm{Cl}$ of difference & Significant? & Summary & \multicolumn{3}{|l|}{$p$ value } \\
\hline DMEM vs DMEM/F12 & $-4.973 \pm 0.4619$ & -6.256 to -3.691 & Yes & $* * *$ & \multicolumn{3}{|l|}{0.0004} \\
\hline \multicolumn{8}{|l|}{ BV-2 siRNA qPCR (Fig. 1L) } \\
\hline $\begin{array}{l}\text { Tukey's multiple } \\
\text { comparisons test }\end{array}$ & $\begin{array}{l}\text { Mean } \\
\text { difference }\end{array}$ & $95.00 \% \mathrm{Cl}$ of difference & Significant? & Summary & \multicolumn{3}{|l|}{ Adjusted $p$ value } \\
\hline DMEM vs DMEM/F12 & 3.192 & -0.3346 to 6.718 & No & ns & 0.0719 & $A-B$ & \\
\hline DMEM vs siFat3 & -2.381 & -5.907 to 1.146 & No & ns & 0.1763 & $A-C$ & \\
\hline DMEM/F12 vs siFat3 & -5.572 & -9.099 to -2.046 & Yes & $* *$ & 0.0068 & $B-C$ & \\
\hline \multicolumn{8}{|l|}{$\begin{array}{l}\text { BV-2 NEAAs metals } \\
\text { others qPCR (Fig. } 2 B \text { ) }\end{array}$} \\
\hline $\begin{array}{l}\text { Dunnett's multiple } \\
\text { comparisons test }\end{array}$ & $\begin{array}{l}\text { Mean } \\
\text { difference }\end{array}$ & $95.00 \% \mathrm{Cl}$ of difference & Significant? & Summary & Adjusted $p$ value & $A-?$ & \\
\hline DMEM vs DMEM/F12 & 2.113 & 1.032 to 3.195 & Yes & $* * *$ & 0.0007 & $\mathrm{~B}$ & DMEM/F12 \\
\hline DMEM vs NEAAs & 0.5533 & -0.5281 to 1.635 & No & ns & 0.4259 & $\mathrm{C}$ & NEAAs \\
\hline DMEM vs metals & 0.4133 & -0.6681 to 1.495 & No & ns & 0.6518 & $\mathrm{D}$ & Metals \\
\hline DMEM vs others & 2.113 & 1.032 to 3.195 & Yes & $* * *$ & 0.0007 & $E$ & Others \\
\hline \multicolumn{8}{|l|}{$\begin{array}{l}\text { BV-2 others qPCR } \\
\quad \text { (Fig. } 2 C)\end{array}$} \\
\hline $\begin{array}{l}\text { Dunnett's multiple } \\
\text { comparisons test }\end{array}$ & $\begin{array}{l}\text { Mean } \\
\text { difference }\end{array}$ & $95.00 \% \mathrm{Cl}$ of difference & Significant? & Summary & Adjusted $p$ value & $\mathrm{C}-?$ & \\
\hline DMEM vs DMEM/F12 & 2.858 & 1.779 to 3.936 & Yes & $* * * *$ & $<0.0001$ & $A$ & DMEM/F12 \\
\hline DMEM vs HYP & 6.176 & 5.098 to 7.255 & Yes & $* * * *$ & $<0.0001$ & $\mathrm{~B}$ & HYP \\
\hline DMEM vs biotin & -0.5829 & -1.661 to 0.4955 & No & ns & 0.4517 & $\mathrm{D}$ & Biotin \\
\hline DMEM vs linoleic & 1.584 & 0.5057 to 2.663 & Yes & $* *$ & 0.0038 & $E$ & Linoleic \\
\hline DMEM vs VB12 & -0.9733 & -2.052 to 0.1052 & No & ns & 0.0839 & $\mathrm{~F}$ & VB12 \\
\hline DMEM vs lipoic & -0.6831 & -1.761 to 0.3954 & No & ns & 0.3094 & G & Lipoic \\
\hline \multicolumn{2}{|l|}{ qPCR (Figure 2/) } & & & & & & \\
\hline $\begin{array}{l}\text { Dunnett's multiple } \\
\text { comparisons test }\end{array}$ & $\begin{array}{l}\text { Mean } \\
\text { difference }\end{array}$ & $95.00 \% \mathrm{Cl}$ of difference & Significant? & Summary & Adjusted $p$ value & A-? & \\
\hline DMEM vs DMEM/F12 & 1.35 & 0.629 to 2.06 & Yes & $* *$ & 0.003 & B & DMEM/F12 \\
\hline DMEM vs HYP & 1.15 & 0.436 to 1.87 & Yes & $* *$ & 0.007 & $\mathrm{C}$ & HYP \\
\hline
\end{tabular}

FAT3 mRNA expression. When BV2 were cultured with DMEM/F12, FAT3 expression was clearly enhanced. However, DMEM containing either "non-essential amino acids" or "metallic ions" has little effect on the expression of FAT3. On the other hand, treatment of BV2 cells with "the others" enhanced FAT3 expression (Fig. 2B), indicating that the specific factor contained in "the others" is required for the FAT3 expression. Next, we surveyed which factors in "the others" regulate BV2 morphology. To answer this question, we additionally divided "the others" into five factors (i.e., hypoxanthine, biotin, vitamin B12, linoleic acid, and lipoic acid) and treated the cells with these compounds individually. Accordingly, treatment with hypoxanthine clearly induced FAT3 expression; however, other factors such as biotin, vitamin B12, linoleic acid, and lipoic acid did not have significant influences on the induction of FAT3 expression (Fig. 2C). Moreover, hypoxanthine stimulation enhances the expression of FAT3 as well as DMEM/F12 culture conditions (Fig. 2D). Subsequently, to examine whether hypoxanthine is sufficient for the morphologic changes of BV2, we quantified the elongated shape of BV2 cells in the presence or absence of hypoxanthine. BV2 morphology exhibited an elongated shape in the DMEM containing hypoxanthine (Fig. 2E-G). To further confirm whether hypoxanthine enhances FAT3 expression in microglia, we purified the primary microglia from neonatal mice brains. Treatment with hypoxanthine increased FAT3 expression in primary microglia, as well as BV2 cells (Fig. $2 H, I)$. These data suggest that hypoxanthine is a key mediator that induces FAT3 expression in microglia.

\section{Intracellular hypoxanthine is crucial for BV2 morphologic changes}

It has been known that $\mathrm{P} 2 \mathrm{X}$ purinergic receptors play an important role in microglial functions. Then, we investigated whether the P2X purinergic receptor is a target of extracellular hypoxanthine using $\mathrm{P} 2 \mathrm{X}$ purinergic receptor antagonist, PPADS (Fig. 3A). Consequently, PPADS did not significantly block hypoxanthine-induced morphologic changes of BV2 (Fig. $3 B-D$ ), implying that the P2X purinergic receptors have little effect on BV2 morphologic changes depending on extracellular hypoxanthine. Because incubation with either DMEM/F12 or hypoxanthine slightly increased a concentration of intracellular hypoxanthine (Fig. 3E), we investigated whether intracellular hypoxanthine regulates microglial morphology. It has been reported that treatment with an equilibrative nucleoside transporter (ENT) inhibitor, dipyridamole 
A

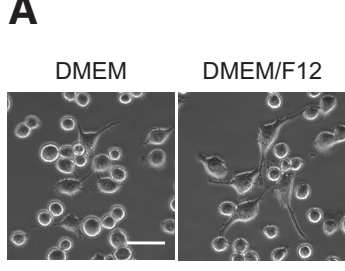

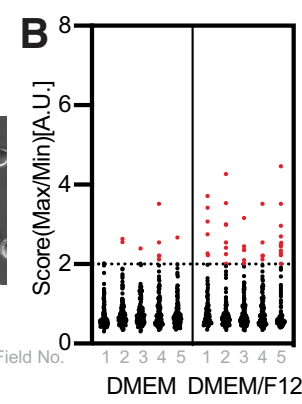

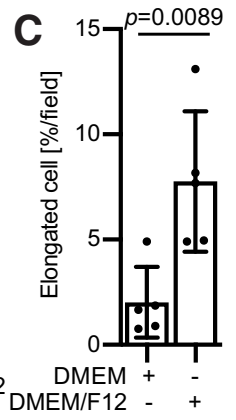

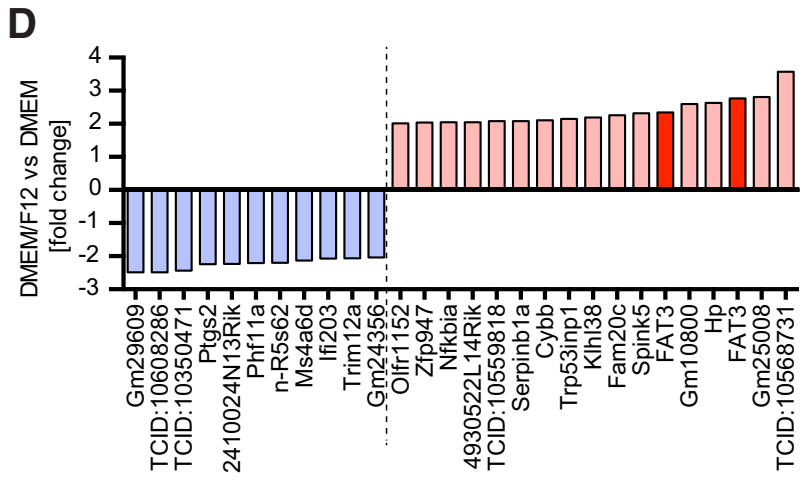

E

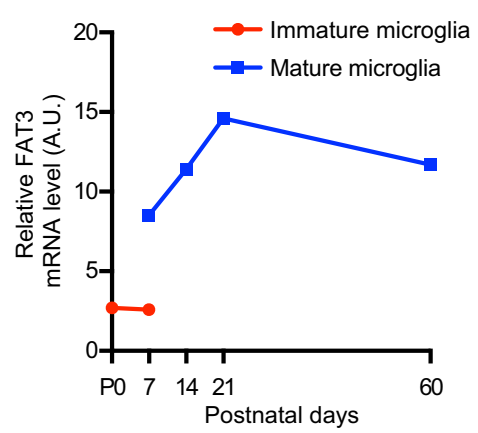

$\mathbf{F}$

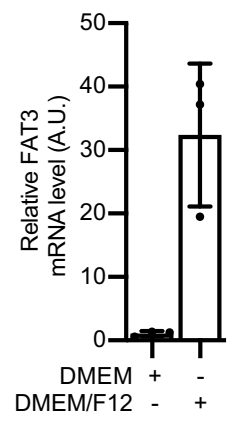

G

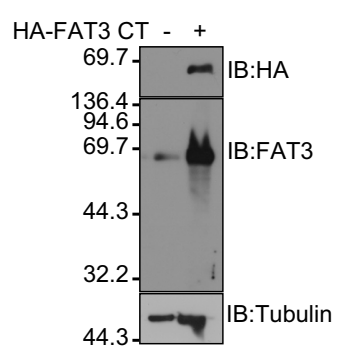

H
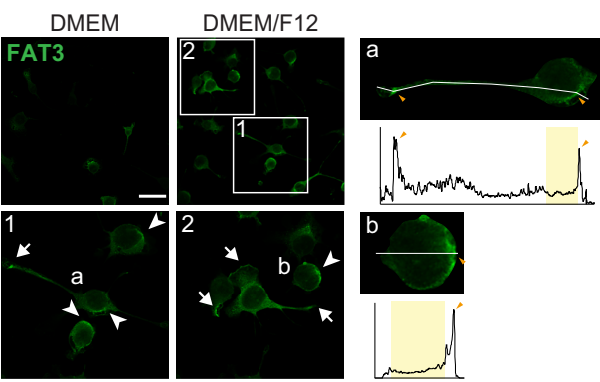

I

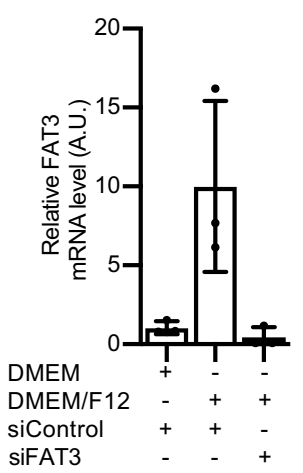

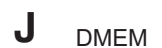
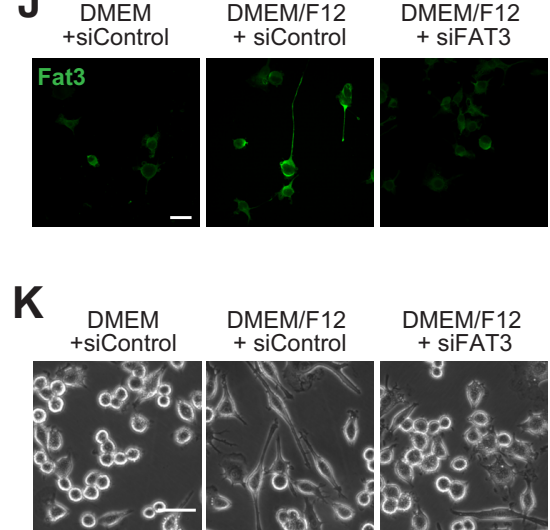

L

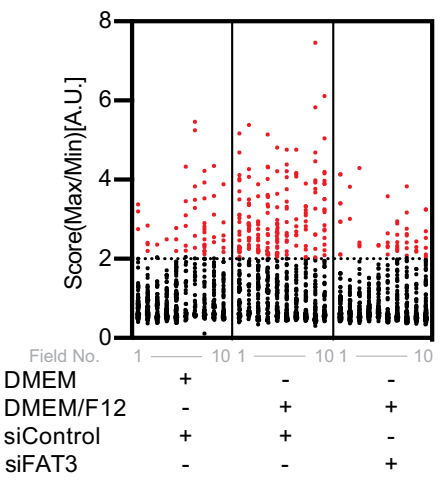

M

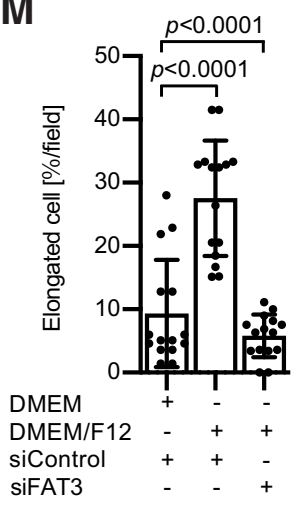

Figure 1. FAT3 regulates BV2 morphology. $\boldsymbol{A}, \mathrm{BV} 2$ cells were incubated with either DMEM as control medium or high-nutrient medium, DMEM/F12 for $24 \mathrm{~h}$. Scale bar: $50 \mu \mathrm{m}$. $\boldsymbol{B}$, Quantification of data from $\boldsymbol{A}$. The score indicates a ratio of maximum to minimum Feret diameter; $n>78$ cells; 5 fields. The elongated cell is defined as the score over 2 . $\boldsymbol{C}$, The graph shows the relative percentage of the elongated cells in each field; $n=5$ fields; mean \pm SD; $p$ value was calculated by Student's $t$ test. The data were reproduced in at least five independent experiments. $\boldsymbol{D}$, A subset of mRNAs identified in microarray experiments. The graph indicates the top 17 of most upregulated and 11 of most downregulated genes under DMEM/F12 culture condition. $\boldsymbol{E}$, The graph indicates in silico analysis of microglial FAT3 expression level from P0 to P60 in mice. The values were obtained from the Brain RNA-Seq database (http:// www.brainrnaseq.org/). The red line indicates immature microglia (Tmem119- cells), and the blue line indicates mature microglia (Tmem $119^{+}$cells). $\boldsymbol{F}$, BV2 cells were incubated with either DMEM/F12 or DMEM for $24 \mathrm{~h}$. FAT3 mRNAs were measured by quantitative RT-PCR analysis and normalized to $5 \mathrm{~S}$ ribosomal RNA; $n=3$; mean $\pm \mathrm{SD}$. The data were reproduced in at least four independent experiments. G, HEK293T cells were transfected with HA-FAT3 CT (4313-4589) and subjected to immunoblot analysis with antiFAT3, anti-HA, and anti-tubulin antibodies. $\boldsymbol{H}$, left, BV2 cells were incubated with either DMEM/F12 or DMEM for $24 \mathrm{~h}$. Immunostaining showing the localization of FAT3 cultured in either DMEM or DMEM/F12. Arrow, FAT3 expression in the distal processes and the edge of lamellipodia. Arrowhead, FAT3 in the proximal region. Scale bar: $50 \mu \mathrm{m}$. Right, The line profiles of FAT3 staining. The yellow areas indicate the nuclei regions. The orange arrowheads indicate accumulated FAT3 regions. $I$, BV2 cells were incubated for $24 \mathrm{~h}$ after transfection of FAT3 siRNA. FAT3 mRNAs were measured by quantitative RT-PCR analysis and normalized to $5 \mathrm{~S}$ ribosomal RNA; $n=3$; mean $\pm \mathrm{SD}$. The data were reproduced in at least three independent experiments. $\boldsymbol{J}$, Immunostaining showing the FAT3 localization in the presence or absence of FAT3 siRNA for $24 \mathrm{~h}$. Scale bar: $50 \mu \mathrm{m}$. $\boldsymbol{K}$, BV2 cells were incubated in the presence or absence of FAT3 siRNA for $24 \mathrm{~h}$. Scale bar: $50 \mu \mathrm{m}$. $\boldsymbol{L}$, Quantification of data from $\boldsymbol{K}$. The score indicates a ratio of 
continued

maximum to minimum Feret diameter; $n>32$ cells; 10 fields. The elongated cell is defined as the score over 2 . $\boldsymbol{M}$, The graph shows the relative percentage of the elongated cells in each field; $n=10$ fields; mean \pm SD; $p$ value was calculated by one-way ANOVA. The data were reproduced in at least three independent experiments.

A

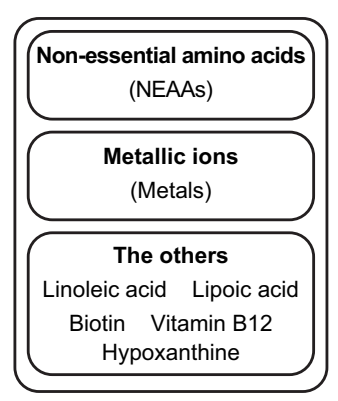

B

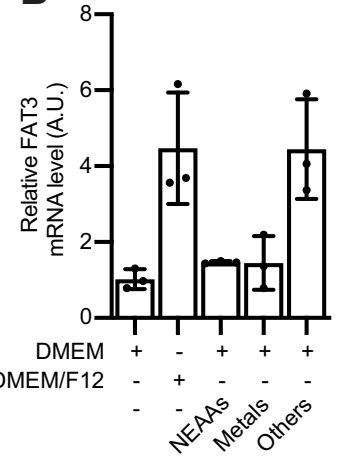

D

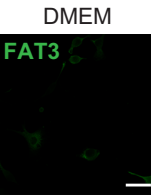

DMEM/F12

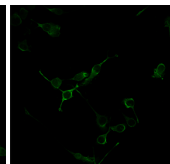

E

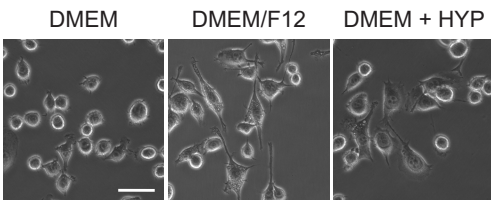

H

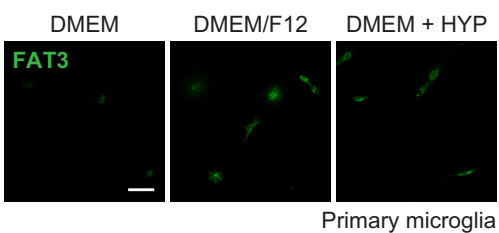

DMEM + HYP

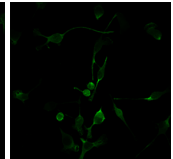

Primary microglia
C

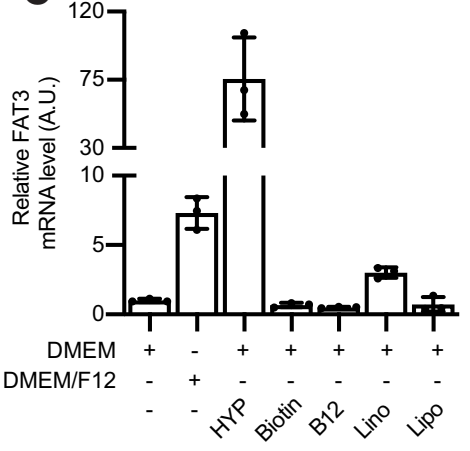

$F$

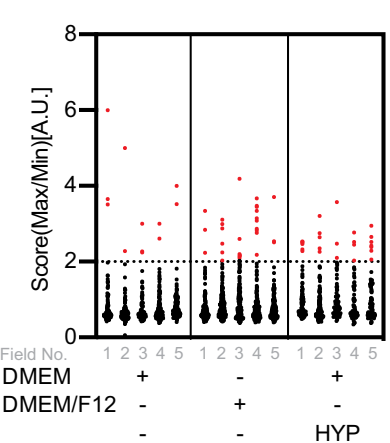

G

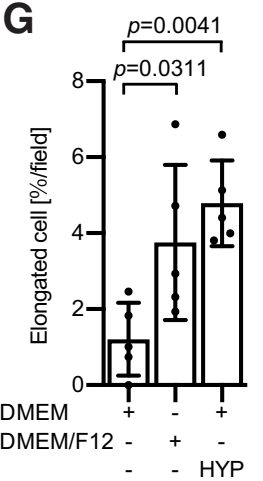

I

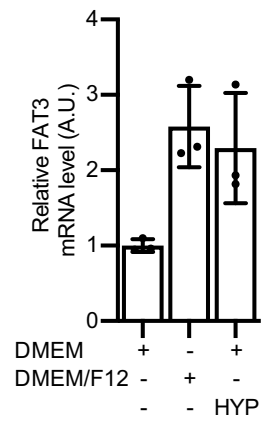

Figure 2. Hypoxanthine promotes FAT3 expression in microglia. $\boldsymbol{A}$, The chart summarizes the additional components of DMEM/F12 against DMEM. They are categorized into three large groups, non-essential amino acids (NEAAs), metallic ions (metals), and the others. B, BV2 cells were incubated with the indicated components for $24 \mathrm{~h}$. FAT3 mRNAs were measured by quantitative RT-PCR analysis and normalized to $5 \mathrm{~S}$ ribosomal RNA; $n=3$; mean \pm SD. The data were reproduced in at least three independent experiments. C, BV2 cells were incubated with $15 \mu \mathrm{M}$ hypoxanthine (HYP), $0.5 \mu \mathrm{M}$ vitamin B12 (B12), $15 \mathrm{nM}$ biotin, $0.15 \mu \mathrm{M}$ linoleic acid (Lino), or $0.5 \mu \mathrm{M}$ lipoic acid (Lipo) for $24 \mathrm{~h}$. The FAT3 mRNAs were measured by quantitative RT-PCR analysis and were normalized to 5 S ribosomal RNA; $n=3$; mean \pm SD. The data were reproduced in at least four independent experiments. $\boldsymbol{D}$, BV2 cells were incubated with either DMEM, DMEM/F12, or DMEM with $15 \mu \mathrm{M}$ hypoxanthine for $24 \mathrm{~h}$. Immunostaining showing the FAT3 localization in the presence or absence of $15 \mu \mathrm{M}$ hypoxanthine. Scale bar: $50 \mu \mathrm{m}$. E. Phase contrast images showing BV2 morphology. Scale bar: $50 \mu \mathrm{m}$. $\boldsymbol{F}$, Quantification of data from $\boldsymbol{E}$. The score indicates a ratio of maximum to minimum Feret diameter; $n>68$ cells; 5 fields. The elongated cell is defined as the score over 2. G. The graph shows the relative percentage of the elongated cells in each field; $n=5$ fields; mean $\pm \mathrm{SD} ; p$ value was calculated by one-way ANOVA. The data were reproduced in at least four independent experiments. $\boldsymbol{H}$, The primary microglia were incubated with either DMEM, DMEM/F12, or DMEM with $15 \mu \mathrm{M}$ hypoxanthine for 24 h. Immunostaining showing the FAT3 expression in the presence or absence of $15 \mu \mathrm{M}$ hypoxanthine. Scale bar: $50 \mu \mathrm{m}$. I, The primary microglia were incubated with either DMEM, DMEM/F12, or DMEM with $15 \mu \mathrm{M}$ hypoxanthine for $24 \mathrm{~h}$. FAT3 mRNAs were measured by quantitative RT-PCR analysis and normalized to $5 \mathrm{~S}$ ribosomal RNA; $n=3$; mean $\pm \mathrm{SD}$. The data were reproduced in two independent experiments. 
A

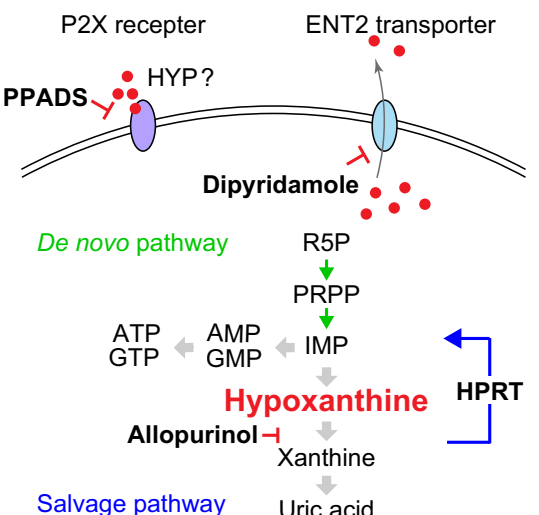

B

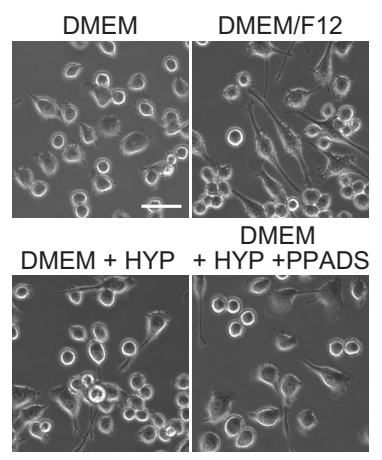

C

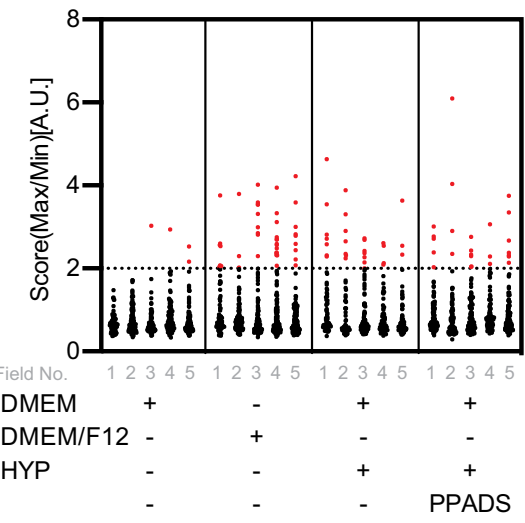

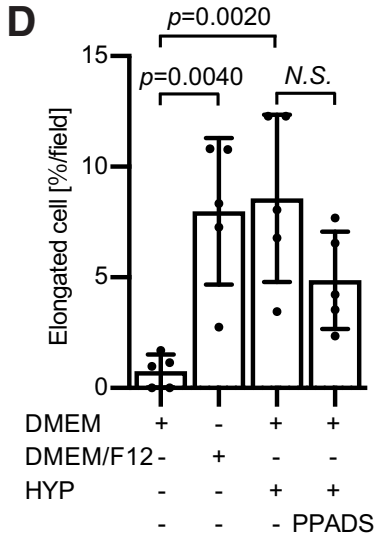

E

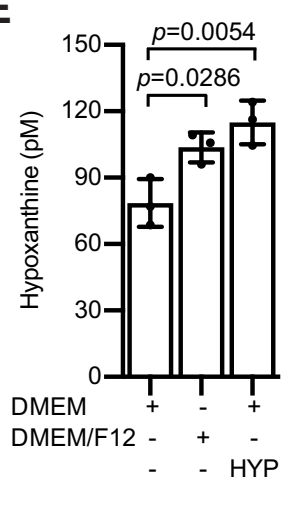

$\mathbf{F}$

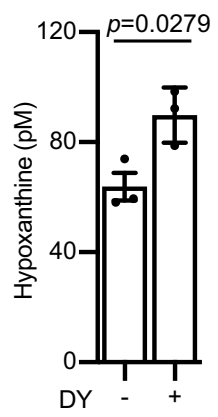

G

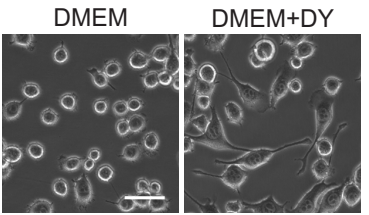

$\mathrm{H}$

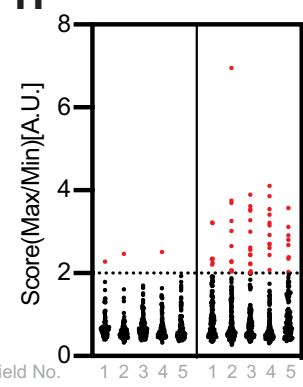

DY
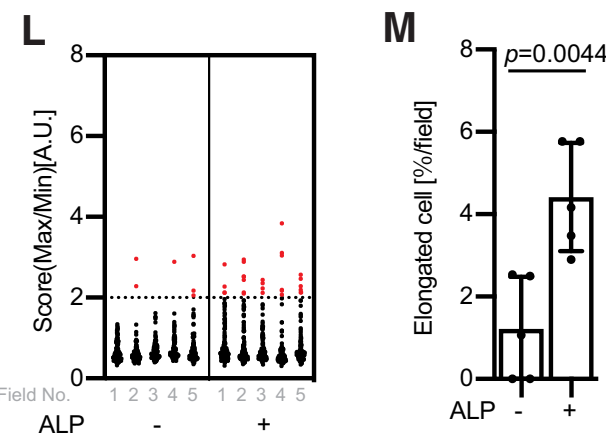

Figure 3. Intracellular hypoxanthine is crucial for BV2 morphologic changes. $\boldsymbol{A}$, Schematic overview of purinergic metabolisms. R5P; ribose 5-phosphate; PRPP, phosphoribosyl pyrophosphate. $\boldsymbol{B}$, BV2 cells were incubated in the presence or absence of $15 \mu \mathrm{M}$ hypoxanthine (HYP) and $10 \mu \mathrm{M}$ PPADS for $24 \mathrm{~h}$. Scale bar: $50 \mu \mathrm{m}$. The data were reproduced in at least three independent experiments. C, Quantification of data from B. The score indicates a ratio of maximum to minimum Feret diameter; $n>57$ cells; 5 fields. The elongated cell is defined as the score over 2. $\boldsymbol{D}$, The graph indicates the relative percentage of elongated BV2 cells in $\boldsymbol{C} ; n=5$ fields; mean \pm SD; $p$ value was calculated by one-way ANOVA. N.S., not significant. The data were reproduced in at least two independent experiments. $\boldsymbol{E}$, The graph indicates the intracellular hypoxanthine concentration cultured in DMEM, DMEM/F12, or DMEM with $15 \mu \mathrm{M}$ hypoxanthine for $3 \mathrm{~h} ; n=3$; mean $\pm \mathrm{SD} ; p$ value was calculated by one-way ANOVA. The data were reproduced in at least two independent experiments. $\boldsymbol{F}$, The graph indicates the intracellular hypoxanthine concentration in BV2 cells cultured in DMEM in the presence or absence of $10 \mu \mathrm{M}$ DY for $3 \mathrm{~h}$. Mean \pm SD; $p$ value was calculated by Student's $t$ test. G, BV2 cells were incubated in the presence or absence of $10 \mu \mathrm{M}$ DY cultured in DMEM for $24 \mathrm{~h}$. Scale bar: $50 \mu \mathrm{m}$. $\boldsymbol{H}$, Quantification of data from $G$. The score indicates a ratio of maximum to minimum Feret diameter; $n>79$ cells; 5 fields. The threshold of the elongated cells was defined by setting over 2 . I, The graph indicates the relative percentage of elongated BV2 cells with or without DY in $\boldsymbol{H} ; n=5$ fields; mean \pm SD; $p$ value was calculated by Student's $t$ test. The data were reproduced in at least three independent experiments. $\boldsymbol{J}$, The graph indicates the intracellular hypoxanthine concentration in the presence or absence of $10 \mu \mathrm{M}$ ALP cultured in DMEM for $3 \mathrm{~h} ; n=5$; mean $\pm \mathrm{SD} ; p$ value was calculated by Student's $t$ test. The data were reproduced in at least two independent experiments. $\boldsymbol{K}$, BV2 cells were incubated in the presence or absence of $10 \mu \mathrm{M}$ ALP cultured in DMEM for $24 \mathrm{~h}$. Scale bar: $50 \mu \mathrm{m}$. 
continued

$\boldsymbol{L}$, Quantification of data from $\boldsymbol{K}$. The score indicates a ratio of maximum to minimum Feret diameter; $n>79$ cells; 5 fields. The elongated cell is defined as the score over 2 . $\boldsymbol{M}$, The graph indicates the relative percentage of elongated BV2 cells in $\boldsymbol{L} ;$; $n=5$ fields; mean $\pm \mathrm{SD} ; p$ value was calculated by Student's $t$ test. The data were reproduced in at least three independent experiments.

(DY), is capable of increasing intracellular hypoxanthine via blocking export hypoxanthine (Robillard et al., 2008; Fig. 3A). We confirmed whether DY increases a concentration of intracellular hypoxanthine in BV2 cells. We find that DY application slightly but significantly increased the hypoxanthine in BV2 cells (Fig. 3F). Using this condition, we quantified the BV2 morphology. The elongated BV2 cells were increased after the treatment with DY (Fig. 3GI), implying that the intracellular concentration of hypoxanthine has an influence on BV2 morphology. To further confirm this, we used another inhibitor, allopurinol (ALP), which is a xanthine oxidase inhibitor (Fig. $3 A$ ). Since the xanthine oxidase is known to catalyze hypoxanthine to xanthine, inhibiting this enzyme also accumulates hypoxanthine in cells (Fig. 3J). As we expected, treatment with ALP increased the elongated shape of BV2 cells (Fig. $3 K-M)$. Taken together, these data suggest that upregulations of intracellular hypoxanthine promote morphologic changes of BV2 cells.

\section{Hypoxanthine-FAT3 pathway controls the BV2 morphologic dynamics in concert with a humoral factor}

Microglial morphology is highly dynamic even in the resting state (Nimmerjahn et al., 2005). Since FAT3 is expressed at the timing of microglial transition (Bennett et al., 2016), we expected that our findings provide potential clues that underlie their morphologic changes. Then, we investigated the mechanisms by which BV2 shapes were changed over time using live-cell imaging analyses (Fig. $4 A-C$; Movies 1, 2). The morphologic changes of BV2 were highly dynamic, and BV2 constantly shuttle between round and elongated shapes. Interestingly, treatment with hypoxanthine slightly but significantly prolonged the retention time of elongation forms, suggesting that FAT3 sustains elongated shapes and inhibits their retraction.

We next investigated the mechanisms of how BV2 shape is stabilized in the presence of hypoxanthine. Since a number of elongated BV2 were observed in low density cultured with DMEM/F12, we speculate that BV2 morphology is regulated by not only a cell-cell interaction but also a humoral factor, which is a potential ligand for FAT3. To answer this question, we cultured BV2 cells with or without the replacements of the medium. Consistent with our findings in Figure 1, both hypoxanthine and DMEM/ F12 promoted the morphologic changes. On the other hand, the number of the round shape of BV2 was increased even in the DMEM/F12 condition and DMEM containing hypoxanthine when the medium was exchanged frequently (Fig. 4D-H). At least in this condition, it seems that an adequate amount of FAT3 was expressed when cells were incubated with DMEM/F12 for $24 \mathrm{~h}$. Therefore, hypoxanthine-induced FAT3 expression is not sufficient for altering BV2 morphology further, implying that BV2 morphologic changes are mediated by the extracellular factors as well. Probably, both a secreted humoral factor and hypoxanthine-induced FAT3 are necessary for regulating BV2 morphogenesis.

\section{Discussion}

In this study, we propose that the FAT atypical cadherin family protein, FAT3, is a novel mediator that controls the morphology of microglia cell line BV2. We also found that hypoxanthine induces FAT3 expression. Moreover, FAT3 in concert with a potential humoral factor suppresses the retraction of their processes. Thus, it is likely that the hypoxanthine-Fat3 axis is crucial for regulating the microglial morphologic changes (Fig. 5).

In the nervous systems, cadherin family proteins, including FAT-related protein, play an important role in regulating a variety of neuronal aspects, such as neuron-glia interaction, synaptogenesis, axon patterning, and dendritic arborization (Takeichi, 2007). So far, it has been shown that FAT3 and FAT1 are thought to be involved in actin rearrangement through interacting with ENANASP proteins (Moller et al., 2004; Tanoue and Takeichi, 2004; Krol et al., 2016). Interestingly, FAT3 subcellular localization is not uniform but limited in a specific site. For instance, FAT3 has been reported to be asymmetrically localized to the processes in the inner plexiform layer in retinal amacrine cell precursors. The opposite processes of amacrine cells are retracted, resulting in forming unipolar cells (Deans et al., 2011; Krol et al., 2016). In accordance with this research, we found that FAT3 in microglia is necessary for stabilizations of the processes in BV2 cells (Fig. 4A-C). Moreover, we observed that FAT3 subcellular localization does not tend to be diffusive at the peripheral region but concentrated locally. Therefore, we considered that asymmetric FAT3 anchors actin-related protein such as ENAVASP and controls the actin rearrangement under the FAT3-expressed region. As FAT-related proteins contribute to homophilic or heterophilic cell adhesion (Nakayama et al., 2002; Ishiuchi et al., 2009), FAT3-interacting protein may have influences on the cell-cell contact or actin organization. So far, it has been reported that Drosophila Fat protein interacts with another cadherin family protein Dachsous (Ds), contributing to the regulation of planar cell polarity (Matakatsu and Blair, 2004). Intriguingly, the functions of both Fat and Ds are regulated by Four-jointed, which phosphorylates the Fat and Ds in the Golgi apparatus (Ishikawa et al., 2008). We found that expression level of FAM20C, which is a secretary kinase as well as Four-jointed, is also increased when BV2 cells are cultured under DMEM/F12 medium (Fig. 1D). Therefore, it may be possible that a high-nutrient condition could promote expressions of not only FAT3 but also FAM20C, leading to enhancing the interaction between FAT3 and target cadherin via FAT3 phosphorylation. 
A

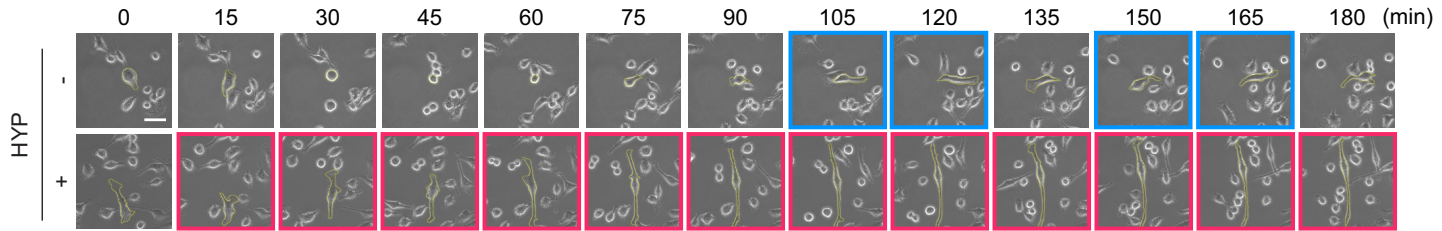

B

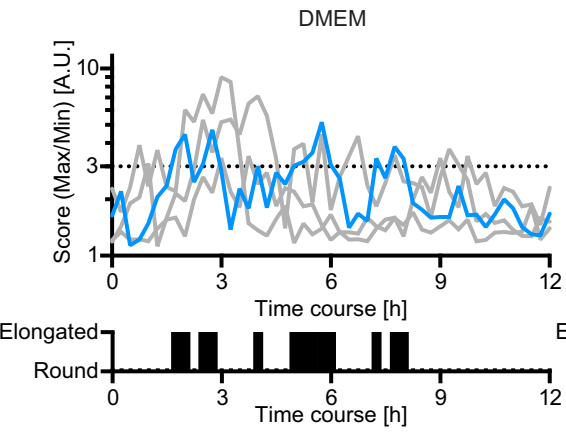

D
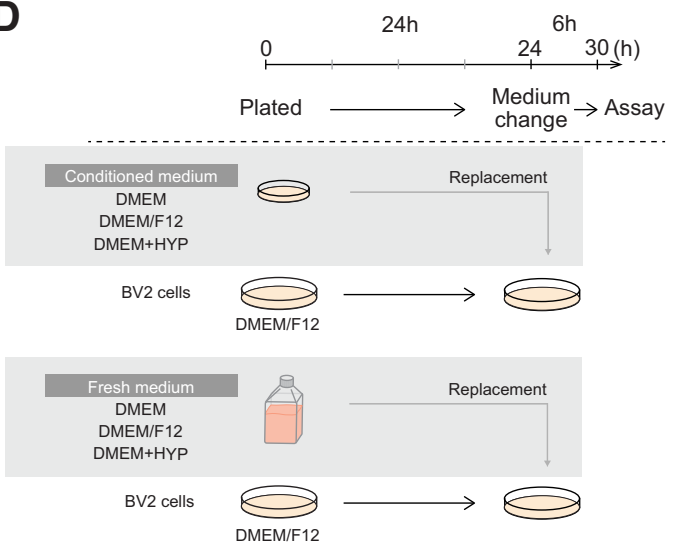

G

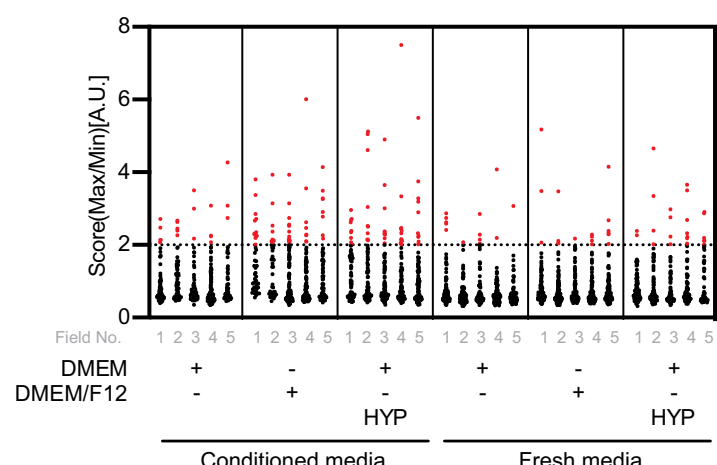

C
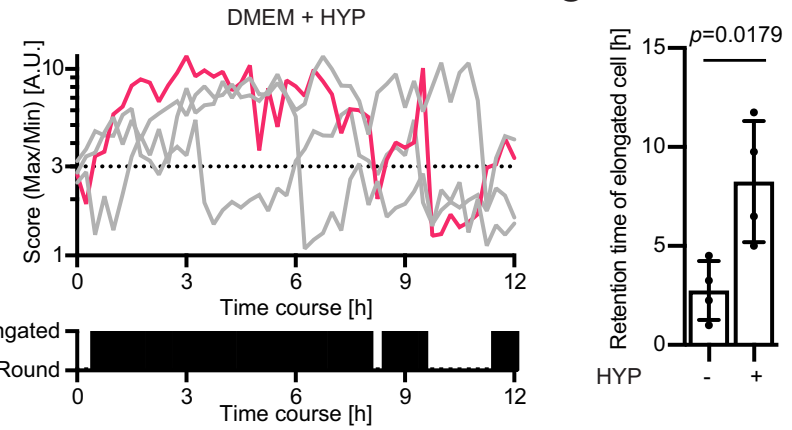
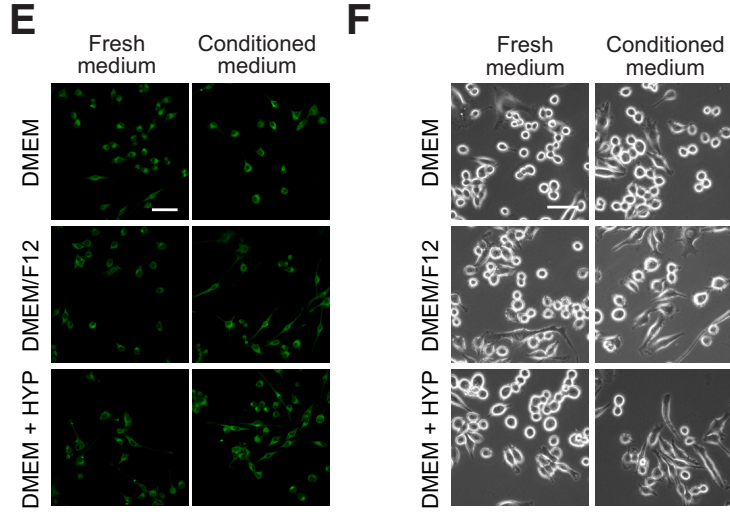

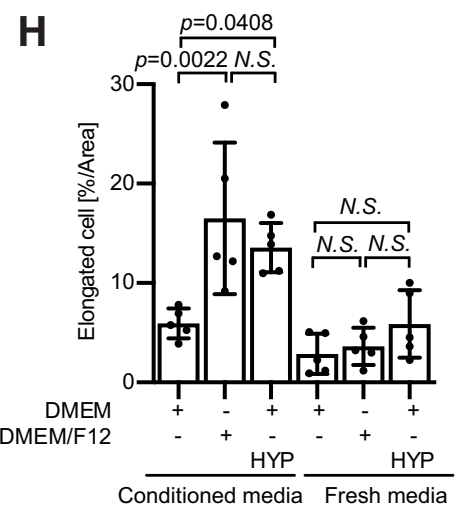

Figure 4. Hypoxanthine-FAT3 pathway controls the BV2 morphologic dynamics in concert with a humoral factor. $\boldsymbol{A}$, BV2 cells were imaged at one frame per $15 \mathrm{~min}$ over for $12 \mathrm{~h}$ with $1.0 \mu \mathrm{g} / \mu \mathrm{l}$ LPS in the presence or absence of $15 \mu \mathrm{M}$ hypoxanthine (HYP). Representative images are shown. The blue and red lines indicate the elongated states. Scale bar: $20 \mu \mathrm{m}$. $\boldsymbol{B}$, The graph indicates the ratio of maximum to minimum Feret diameter. $\boldsymbol{C}$, The graph is summarized by data in $\boldsymbol{B} ; n=4$; mean \pm SD; $p$ values were calculated by Student's $t$ test. The data were reproduced in at least three independent experiments. $\boldsymbol{D}$, Scheme of experiment. BV2 cells were incubated with DMEM/F12 medium for $24 \mathrm{~h}$ and were then replaced with either conditioned or fresh media for $24 \mathrm{~h}$. For the conditioned media, other BV2 cells were incubated for $24 \mathrm{~h}$ using indicated media. $\boldsymbol{E}$, BV2 cells were incubated for $6 \mathrm{~h}$ after exchanging media and were then subjected to immunocytochemistry. Immunostaining showing the expression level of FAT3. It seems that FAT3 expression is maintained after changing the media. Scale bar: $50 \mu \mathrm{m}$. $\boldsymbol{F}$, Phase contrast images showing BV2 
continued

morphology. Scale bar: $50 \mu \mathrm{m}$. G. The score indicates a ratio of maximum to minimum Feret diameter; $n>39$ cells; 5 fields. The elongated cell is defined as the score over 2. $\boldsymbol{H}$, The graph indicates the relative percentage of elongated BV2 cells morphology in $\boldsymbol{F} ; n=5$ fields; mean $\pm \mathrm{SD} ; p$ values were calculated by one-way ANOVA. N.S., not significant. The data were reproduced in at least two independent experiments.

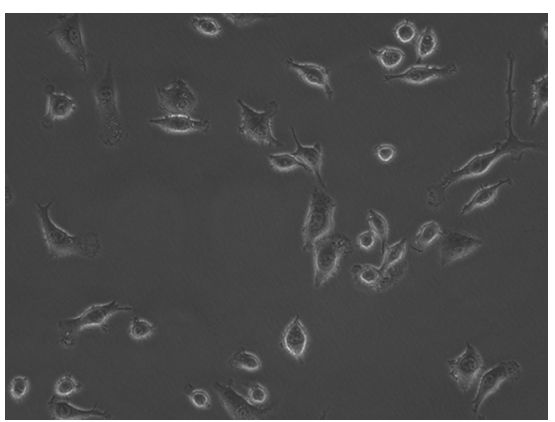

Movie 1. The time-lapse recoding of BV2 cells in the absence of hypoxanthine in Fig. 4A. [View online]

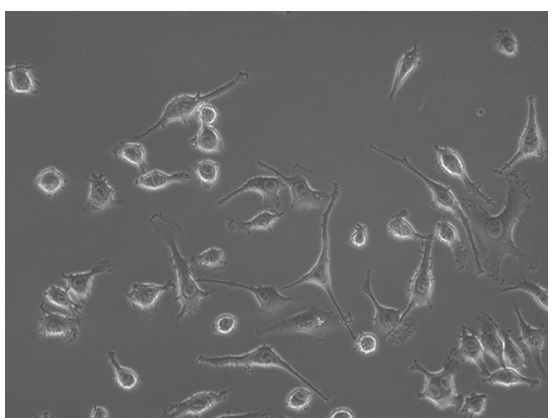

Movie 2. The time-lapse recoding of BV2 cells in the presence of hypoxanthine in Fig. 4A. [View online]

Meanwhile, we found that the humoral factors secreted from BV2 cells have influences on their morphologic changes (Fig. 4D-H). Since proteomic analyses had revealed that FAT3 is associated with several humoral factors, such as XCL1 and PDGFB (Huttlin et al., 2017), the FAT3dependent morphologic changes is regulated by not only cell-cell interaction but also other extracellular proteins.

Although several purinergic receptors exist in microglia, we consider that microglial morphology relies on intracellular hypoxanthine for the following reasons; First, PO purinergic receptors do not recognize hypoxanthine (Bender et al., 2002). Second, treatment with PPADS, which is an antagonist for P2X receptors, had little effect on changing BV2 morphology. Third, increasing intracellular hypoxanthine induces morphologic changes of BV2. An important question is how hypoxanthine mediates FAT3 expression. It has been known that hypoxanthine mediates salvage pathways to synthesize nucleotides. Hypoxanthine-guanine phosphoribosyl transferase (HPRT1), which catalyzes hypoxanthine to inosine monophosphate (IMP) is one of the key enzymes that regulate the salvage pathway. Previously, HPRT1 expression level has been reported to be changed in microglia around P14 (Bennett et al., 2016). The proteomics analyses have revealed that HPRT1 interacts with several transcription factors, such as Jun and NF- $\kappa$ B (Li et al., 2015). Thus, it could be possible that hypoxanthine regulated HPRT1 cooperates with these transcription factors and upregulates FAT3 expression. Intriguingly, mutations in Hprt1 gene cause Lesch-Nyhan syndrome (LNS) (Yang et al., 1984), which is a rare neurologic disorder exhibiting accumulation of uric acid caused by a defect in nucleic acid metabolisms. Because a decrease of uric acid accumulation does not cure the LNS symptoms, there is another possibility that aberrant microglial functions via abnormal hypoxanthine metabolism may cause neurologic disorders. The salvage pathway, rather than the de novo pathway, functions preferentially in the adulthood brain. On the other hand, it seems that the de novo pathway is activated dominantly under the postnatal stage, indicating that the switching from the de novo to the salvage pathways could occur after birth. Given that the upregulation of intracellular hypoxanthine concentration promotes HPRT1 activity, HPRT1 activation could be a key event that triggers the microglial transition under postnatal brains. Thus, it may be possible that loss of HPRT1 function causes the aberrant microglial transition, resulting in the onset of neuropsychiatric disorders, such as LNS.

BV2 cells are often used to be in place of primary microglia in an in vitro experiment because the gene expression
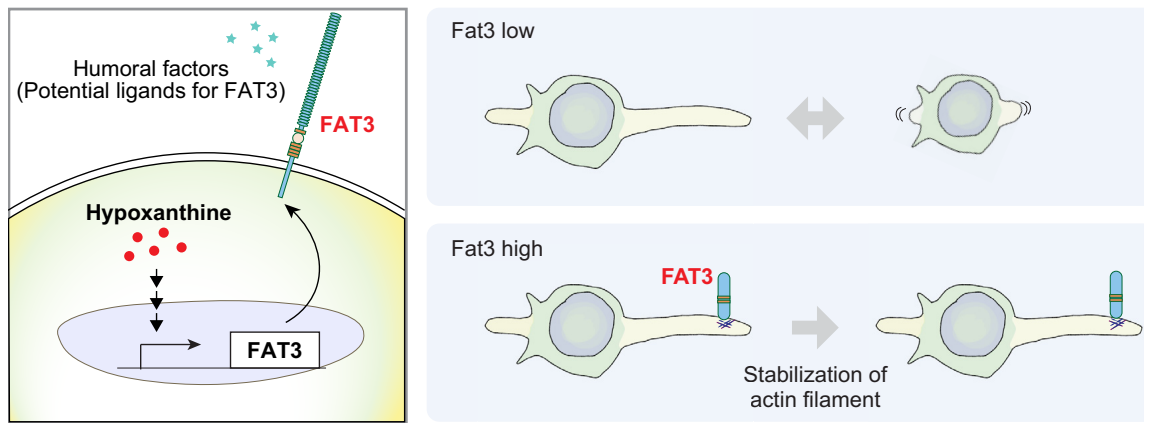

Figure 5. A model describing the functions of FAT3 in microglia. FAT3 expression is induced by hypoxanthine in microglia. FAT3 localized on the tip of the microglial process may stabilize actin reorganization in concert with a humoral factor. 
patterns in BV2 cells are similar to the primary microglia under the reactive state (Henn et al., 2009). In addition, the analyses of BV2 cells have contributed to understanding the molecular mechanisms of intracellular and intercellular phenomena, such as caspase signaling dependent microglia activation (Burguillos et al., 2011), the microglia and glioblastoma communication (Shen et al., 2016), and microglial phagocytosis (Pluvinage et al., 2019). Moreover, BV2 cells are used to facilitate investigating the mechanisms of the neuronal disorder, such as Alzheimer's disease, Huntington's disease, amyotrophic lateral sclerosis, and stroke (Urushitani et al., 2006; Burguillos et al., 2015; Zhao et al., 2018; Joshi et al., 2019; Pluvinage et al., 2019), indicating that BV2 cells are a powerful tool to study the microglial functions. On the other hand, the shape of surveillant microglia in vivo is different from in BV2 cells.

FAT3 has been reported to be localized at the process in retinal amacrine cells and suppresses their retraction. Since FAT3 interacts with ENANASP protein, it is likely that FAT3 regulates a local actin reorganization in neurons. As well as amacrine cells, we found that treatment with hypoxanthine stabilizes their morphology of BV2 cells. Thus, we presume that one of FAT3 functions is to control actin rearrangement and stabilize processes locally. The interesting question is how subcellular localization of FAT3 is regulated. Since FAT3 is a cadherin family protein, the target proteins expressed in other cells could influence on subcellular localization of microglial FAT3. Although this is an interesting enigma, a detailed analysis will be a need in the future.

In conclusion, we found that FAT3 regulates BV2 morphology in coordination with a humoral factor derived from BV2 cells. The expression level of FAT3 in BV2 is regulated by intracellular hypoxanthine in microglia, demonstrating that the hypoxanthine-FAT3 axis is a novel pathway that links microglial morphologic changes to their traits. Since defects in Fat3 gene are associated with several neuropsychiatric diseases, such as schizophrenia, autism, and ataxia (Yan et al., 2016; Baron et al., 2019; Capkova et al., 2019), our finding may provide a hint that links microglial dysregulations to the onset of these diseases.

\section{References}

Baron O, Grieshober D, Dias C, Fanto M (2019) Fat cadherins in mouse models of degenerative ataxias. Sci Rep 9:16155.

Bender E, Buist A, Jurzak M, Langlois X, Baggerman G, Verhasselt P, Ercken M, Guo HQ, Wintmolders C, Van den Wyngaert I, Van Oers I, Schoofs L, Luyten W (2002) Characterization of an orphan $G$ protein-coupled receptor localized in the dorsal root ganglia reveals adenine as a signaling molecule. Proc Natl Acad Sci USA 99:8573-8578.

Bennett ML, Bennett FC, Liddelow SA, Ajami B, Zamanian JL, Fernhoff NB, Mulinyawe SB, Bohlen CJ, Adil A, Tucker A, Weissman IL, Chang EF, Li G, Grant GA, Hayden Gephart MG, Barres BA (2016) New tools for studying microglia in the mouse and human CNS. Proc Natl Acad Sci USA 113:E1738-E1746.

Burguillos MA, Deierborg T, Kavanagh E, Persson A, Hajji N, GarciaQuintanilla A, Cano J, Brundin P, Englund E, Venero JL, Joseph B (2011) Caspase signalling controls microglia activation and neurotoxicity. Nature 472:319-324.
Burguillos MA, Svensson M, Schulte T, Boza-Serrano A, GarciaQuintanilla A, Kavanagh E, Santiago M, Viceconte N, Oliva-Martin MJ, Osman AM, Salomonsson E, Amar L, Persson A, Blomgren K, Achour A, Englund E, Leffler H, Venero JL, Joseph B, et al. (2015) Microglia-secreted galectin-3 acts as a toll-like receptor 4 ligand and contributes to microglial activation. Cell Rep 10:1626-1638.

Capkova P, Srovnal J, Capkova Z, Staffova K, Becvarova V, Trkova M, Adamova K, Santava A, Curtisova V, Hajduch M, Prochazka M (2019) MLPA is a practical and complementary alternative to CMA for diagnostic testing in patients with autism spectrum disorders and identifying new candidate CNVs associated with autism. PeerJ 6:e6183.

Cunningham CL, Martínez-Cerdeño V, Noctor SC (2013) Microglia regulate the number of neural precursor cells in the developing cerebral cortex. J Neurosci 33:4216-4233.

Deans MR, Krol A, Abraira VE, Copley CO, Tucker AF, Goodrich LV (2011) Control of neuronal morphology by the atypical cadherin Fat3. Neuron 71:820-832.

Fields RD, Burnstock G (2006) Purinergic signalling in neuron-glia interactions. Nat Rev Neurosci 7:423-436.

Gevi F, Zolla L, Gabriele S, Persico AM (2016) Urinary metabolomics of young Italian autistic children supports abnormal tryptophan and purine metabolism. Mol Autism 7:47.

Haynes SE, Hollopeter G, Yang G, Kurpius D, Dailey ME, Gan WB, Julius D (2006) The P2Y12 receptor regulates microglial activation by extracellular nucleotides. Nat Neurosci 9:1512-1519.

Henn A, Lund S, Hedtjärn M, Schrattenholz A, Pörzgen P, Leist M (2009) The suitability of BV2 cells as alternative model system for primary microglia cultures or for animal experiments examining brain inflammation. ALTEX 26:83-94.

Huttenlocher PR, Dabholkar AS (1997) Regional differences in synaptogenesis in human cerebral cortex. J Comp Neurol 387:167178.

Huttlin EL, Bruckner RJ, Paulo JA, Cannon JR, Ting L, Baltier K, Colby G, Gebreab F, Gygi MP, Parzen H, Szpyt J, Tam S, Zarraga G, Pontano-Vaites L, Swarup S, White AE, Schweppe DK, Rad R, Erickson BK, Obar RA, et al. (2017) Architecture of the human interactome defines protein communities and disease networks. Nature 545:505-509.

Ishikawa HO, Takeuchi H, Haltiwanger RS, Irvine KD (2008) Fourjointed is a Golgi kinase that phosphorylates a subset of cadherin domains. Science 321:401-404.

Ishiuchi T, Misaki K, Yonemura S, Takeichi M, Tanoue T (2009) Mammalian Fat and Dachsous cadherins regulate apical membrane organization in the embryonic cerebral cortex. J Cell Biol 185:959-967.

Joshi AU, Minhas PS, Liddelow SA, Haileselassie B, Andreasson KI, Dorn GW 2nd, Mochly-Rosen D (2019) Fragmented mitochondria released from microglia trigger A1 astrocytic response and propagate inflammatory neurodegeneration. Nat Neurosci 22:16351648.

Kettenmann H, Hanisch UK, Noda M, Verkhratsky A (2011) Physiology of microglia. Physiol Rev 91:461-553.

Krol A, Henle SJ, Goodrich LV (2016) Fat3 and Ena/VASP proteins influence the emergence of asymmetric cell morphology in the developing retina. Development 143:2172-2182.

Li X, Wang W, Wang J, Malovannaya A, Xi Y, Li W, Guerra R, Hawke DH, Qin J, Chen J (2015) Proteomic analyses reveal distinct chromatin-associated and soluble transcription factor complexes. Mol Syst Biol 11:775.

Marín-Teva JL, Dusart I, Colin C, Gervais A, van Rooijen N, Mallat M (2004) Microglia promote the death of developing Purkinje cells. Neuron 41:535-547.

Matakatsu H, Blair SS (2004) Interactions between Fat and Dachsous and the regulation of planar cell polarity in the Drosophila wing. Development 131:3785-3794.

Miyamoto A, Wake H, Ishikawa AW, Eto K, Shibata K, Murakoshi H, Koizumi S, Moorhouse AJ, Yoshimura Y, Nabekura J (2016) Microglia contact induces synapse formation in developing somatosensory cortex. Nat Commun 7:12540. 
Moller M, Berg F, Riquet J, Pomp D, Archibald A, Anderson S, Feve K, Zhang Y, Rothschild M, Milan D, Andersson L, Tuggle CK (2004) High-resolution comparative mapping of pig chromosome 4, emphasizing the FAT1 region. Mamm Genome 15:717-731.

Nagae S, Tanoue T, Takeichi M (2007) Temporal and spatial expression profiles of the Fat3 protein, a giant cadherin molecule, during mouse development. Dev Dyn 236:534-543.

Nakayama M, Nakajima D, Yoshimura R, Endo Y, Ohara O (2002) MEGF1/fat2 proteins containing extraordinarily large extracellular domains are localized to thin parallel fibers of cerebellar granule cells. Mol Cell Neurosci 20:563-578.

Nimmerjahn A, Kirchhoff F, Helmchen F (2005) Resting microglial cells are highly dynamic surveillants of brain parenchyma in vivo. Science 308:1314-1318.

Paolicelli RC, Bolasco G, Pagani F, Maggi L, Scianni M, Panzanelli P, Giustetto M, Ferreira TA, Guiducci E, Dumas L, Ragozzino D, Gross CT (2011) Synaptic pruning by microglia is necessary for normal brain development. Science 333:1456-1458.

Pluvinage JV, Haney MS, Smith BAH, Sun J, Iram T, Bonanno L, Li L, Lee DP, Morgens DW, Yang AC, Shuken SR, Gate D, Scott M, Khatri P, Luo J, Bertozzi CR, Bassik MC, Wyss-Coray T (2019) CD22 blockade restores homeostatic microglial phagocytosis in ageing brains. Nature 568:187-192.

Redies C, Hertel N, Hübner CA (2012) Cadherins and neuropsychiatric disorders. Brain Res 1470:130-144.

Robillard KR, Bone DB, Hammond JR (2008) Hypoxanthine uptake and release by equilibrative nucleoside transporter 2 (ENT2) of rat microvascular endothelial cells. Microvasc Res 75:351-357.

Saugstad OD (1988) Hypoxanthine as an indicator of hypoxia: its role in health and disease through free radical production. Pediatr Res 23:143-150.

Schafer DP, Lehrman EK, Kautzman AG, Koyama R, Mardinly AR, Yamasaki R, Ransohoff RM, Greenberg ME, Barres BA, Stevens B (2012) Microglia sculpt postnatal neural circuits in an activity and complement-dependent manner. Neuron 74:691-705.

Shen X, Burguillos MA, Osman AM, Frijhoff J, Carrillo-Jiménez A, Kanatani S, Augsten M, Saidi D, Rodhe J, Kavanagh E, Rongvaux A, Rraklli V, Nyman U, Holmberg J, Östman A, Flavell RA, Barragan A, Venero JL, Blomgren K, Joseph B (2016) Glioma-induced inhibition of caspase-3 in microglia promotes a tumor-supportive phenotype. Nat Immunol 17:1282-1290.
Sierra A, Encinas JM, Deudero JJ, Chancey JH, Enikolopov G, Overstreet-Wadiche LS, Tsirka SE, Maletic-Savatic M (2010) Microglia shape adult hippocampal neurogenesis through apoptosis-coupled phagocytosis. Cell Stem Cell 7:483-495.

Takeichi M (2007) The cadherin superfamily in neuronal connections and interactions. Nat Rev Neurosci 8:11-20.

Tanoue T, Takeichi M (2004) Mammalian Fat1 cadherin regulates actin dynamics and cell-cell contact. J Cell Biol 165:517-528.

Ueno M, Fujita Y, Tanaka T, Nakamura Y, Kikuta J, Ishii M, Yamashita T (2013) Layer V cortical neurons require microglial support for survival during postnatal development. Nat Neurosci 16:543-551.

Urushitani M, Sik A, Sakurai T, Nukina N, Takahashi R, Julien JP (2006) Chromogranin-mediated secretion of mutant superoxide dismutase proteins linked to amyotrophic lateral sclerosis. Nat Neurosci 9:108-118.

Viktorinová I, König T, Schlichting K, Dahmann C (2009) The cadherin Fat2 is required for planar cell polarity in the Drosophila ovary. Development 136:4123-4132.

Yan P, Qiao X, Wu H, Yin F, Zhang J, Ji Y, Wei S, Lai J (2016) An association study between genetic polymorphisms in functional regions of five genes and the risk of schizophrenia. J Mol Neurosci 59:366-375.

Yang TP, Patel PI, Chinault AC, Stout JT, Jackson LG, Hildebrand BM, Caskey CT (1984) Molecular evidence for new mutation at the hprt locus in Lesch-Nyhan patients. Nature 310:412-414.

Zhang Y, Chen K, Sloan SA, Bennett ML, Scholze AR, O'Keeffe S, Phatnani HP, Guarnieri P, Caneda C, Ruderisch N, Deng S, Liddelow SA, Zhang C, Daneman R, Maniatis T, Barres BA, Wu JQ (2014) An RNA-sequencing transcriptome and splicing database of glia, neurons, and vascular cells of the cerebral cortex. J Neurosci 34:11929-11947.

Zhang Y, Sloan SA, Clarke LE, Caneda C, Plaza CA, Blumenthal PD, Vogel $H$, Steinberg GK, Edwards MS, Li G, Duncan JA 3rd, Cheshier SH, Shuer LM, Chang EF, Grant GA, Gephart MG, Barres BA (2016) Purification and characterization of progenitor and mature human astrocytes reveals transcriptional and functional differences with mouse. Neuron 89:37-53.

Zhao $Y$, Wu X, Li X, Jiang LL, Gui X, Liu Y, Sun Y, Zhu B, PiñaCrespo JC, Zhang M, Zhang N, Chen X, Bu G, An Z, Huang TY, Xu $\mathrm{H}$ (2018) TREM2 is a receptor for $\beta$-amyloid that mediates microglial function. Neuron 97:1023-1031.e7. 